\title{
Chemistry and Structures Behind the Brilliant Iridescent Labradorite
}

\author{
SHIYUN JIN ${ }^{1,2^{*}}$, HUIFANG XU AND SEUNGYEOL LEE ${ }^{2,3}$ \\ ${ }^{1}$ Gemological Institute of America, 5345 Armada Drive, \\ Carlsbad, CA 92008, USA \\ (*correspondence: sjin@gia.edu) \\ ${ }^{2}$ Department of Geoscience, University of Wisconsin- \\ Madison, 1215 W. Dayton Street, Madison, WI 53706, \\ USA (hfxu@geology.wisc.edu) \\ ${ }^{3}$ Astromaterials Research and Exploration Directorate, NASA \\ Johnson Space Center, 2101 NASA Parkway, Houston, \\ TX 77058, USA (slee2@lpi.usra.edu)
}

Iridescent labradorite is a unique gem stone that produces brilliant colors by interference of light reflected from the nano-scaled lamellar textures in the crystals, which are known as the Bøggild intergrowth. The nano-texture was postulated and optically studied almost a century ago, long before highresolution electron microscope was available. However, the driving force and mechanism that creates these exsolution lamellae is still not clear after decades of intensive study. Recent studies proposed that the Bøggild intergrowth in iridescent labradorite is produced through a strong first-order phase transformation between the disordered $C \bar{I}$ structure to the incommensurately modulated $e 1$ structure.

Labradorite crystals with iridescent color zoning from different localities are studied and compared. The lamellae textures are characterized with conventional TEM and STEM. The compositions of individual lamellae are analyzed with high-resolution X-ray EDS mapping and atom probe tomography (APT). The results suggest that the Bøggild intergrowth could be caused by the first-order phase boundary gap either between $C \bar{I}$ and $Z \bar{I}$ or between $C \bar{I}$ and $e 1$ phases. The compositional difference between adjacent lamellae range from 10 to $15 \mathrm{~mole} \% \mathrm{An}$, and may vary in the same crystal for areas with different color. The exsolution lamellae are formed through a nucleation and growth process instead of spinodal decomposition as previously believed. The regular lamellar texture is most likely resulting from the strong anisotropy of the labradorite crystal. The iridescent colors, which directly correlate with the average lamellae thickness, are controlled by the bulk composition and cooling rate of the labradorite. A complete phase diagram of the plagioclase feldspar diagram is completed with this last missing piece of the puzzle. 